\title{
Towards an agent-based model of passenger transportation
}

\author{
Banafsheh Hajinasab ${ }^{*}$, Paul Davidsson, Jan A. Persson, Johan Holmgren \\ Department of Computer Science, Malmö University, Sweden \\ \{banafsheh.hajinasab, paul.davidsson, jan.a.persson, \\ johan.holmgren\} @mah.se
}

\begin{abstract}
In this paper, we present a multi-agent based simulation model for supporting the decision making in urban transport planning. The model can be used to investigate how different transport infrastructure investments and policy instruments will affect the travel choices of passengers. We have identified four main categories of factors influencing the choice of travel: cost, time, convenience, and social norm. However, travelers value these factors differently depending on their individual preferences, something that can be modeled in an agent-based model. Moreover, instead of modeling the transport system explicitly, on-line web services are used to generate travel options. The model can support transport planners by providing modal share, as well as economical and environmental consequences. As a first step towards validation of the model, we have conducted a simple case study of three scenarios where we analyze the effects of changes to the public transport fares on commuter's travel choices in the Malmö-Lund region in Sweden.
\end{abstract}

Keywords: multi-agent based simulation, traveler behavior modeling, passenger transport, impact assessment, web services

\section{Introduction}

The design of a "greener" transport system can be supported by a wide set of transport measures, including both transportation policy instruments and investments in infrastructure, such as new public transport pricing schemes, taxes and fares for motorized transport, new bus stops and lines, and new parking space.

In this paper, we propose a novel multi-agent based simulation model for supporting decision making in urban transport planning. The model can be used to investigate how different transport measures affect the decisions of the travelers. It takes into account how factors like cost, time, convenience, and social norm influences the decisions on an individual level depending on the socio-economical features of the individual. Another innovative property of the simulator is that it makes use of on-line web services in order to generate travel options, rather than modeling the transport system explicitly.

adfa, p. 1, 2015.

(c) Springer-Verlag Berlin Heidelberg 2015 
In the next section we review the related work in relation to the new model. Section 3 presents the proposed model. To make a first validation of the model, a simple case study of three scenarios is presented in section 4, where we analyze the effects of changes to the public transport fares on commuter's travel choices in a region of Sweden. The paper is concluded in section 5 .

\section{Related work}

As the application of transport measures may have substantial impact on the travelers' behavior, it is very important to assess their impact before implementation, so that negative effects can be avoided and positive effects can be confirmed. One way of doing this is to perform experimental studies in the real world, but such studies are often very expensive and time-consuming. A common approach for assessing the effects of transport measures is to use computational models, which allows studying the transport system in a simulated environment. A recent review of policy impact assessment models concludes that conventional discrete choice models are the dominating method for travel behavior modeling [7]. Examples of such models are the national transport models often based on the so-called four-step modeling approach. The four steps are: trip generation, where the frequency of trips between zones is determined; trip distribution, where origins are matched with destinations; mode choice, where the proportion of trips between each origin and destination that use a particular transport mode is computed; and route assignment, where all trips are assigned to routes. However, four-step models have been criticized both for neglecting the interaction effects between the involved actors and for oversimplification, which often lead to significant biases in output, especially in settings where the interaction between policies and/or travelers is significant [16]. Furthermore, these models only take into account of a limited number of the factors influencing travel behavior [7].

Agent-based simulation modeling is another approach that has been used for impact assessment of transport measures. Agent-based modeling is often regarded as a bottom-up approach where each traveler is treated as an interacting, autonomous and independent object. Thus, it differs from conventional top-down approaches that focus on overall aggregated analysis of the system's behavior [6,17].

We present an innovative agent-based simulation model for impact assessment of different transport measures, where the passengers are modeled as agents. We generate different travel alternatives of an agent using web services of online travel planners. We consider both motorized and non-motorized modes of transportation and the combinations of them in generating travel alternatives. The model focuses on how to travel when the destination is already decided, i.e., corresponding to steps 3 and 4 of the traditional four-step models. More specifically, we focus on the mode choice, route choice and departure time choices of travelers, when source and destination data is available from the traveler agent, i.e., the traveler's home and work addresses. We believe that significant improvements to these steps can be made using a more detailed bottom-up approach, and that this can be used together with any approach to determine the travel demand. 
The agent-based modeling approach provides a more dynamic approach with respect to the level of detail in modeling different parts. For instance, more interesting parts of the infrastructure can be modeled with a higher granularity. This makes it possible to study the effects of, e.g., building a new bike parking facility that is safe and efficient and close to a train station, or allowing the travelers to bring their bikes on the trains. Furthermore, by using an agent-based method it is possible to model what travel options different travelers actually are aware of, or consider, when deciding what option to choose. This makes it possible to study the effects of, e.g., travel awareness campaigns and the availability of advanced travel planning systems. These interventions are difficult, or even impossible, to study using traditional models.

Furthermore, agent-based models are able to capture time-related aspects, such as the effects of synchronization and optimization of timetables [15]. There are many transport policy measures that concern time, e.g., time-differentiated congestion and parking fees. Such transport policies are difficult to study using traditional models, but they may have an important influence on travel choices.

Using an agent-based approach for modeling travelers, including their behavior and interaction with each other and the surrounding environment, will facilitate capturing each individual's preferences and characteristics. This is critically important in order to determine the actual decisions of individual travelers. Thus, agent-based modeling seems very well suited to predict and analyze the effects of different transport measures, since it explicitly models the decisions of each individual and is able to compute the consequences of these decisions. It should be noted that agentbased modeling might require more information about travelers on an individual level than the traditional models, which to a large extent are based on population averages. However, modern consumer technology like smartphones, as well as ITS services like advanced ticketing and tracking systems based on "Internet of Things" technology (connected devices), enable efficient, large-scale, collection of individual travel data.

There are few studies that have applied an agent-based modeling approach in the context of transport policy analysis [7]. In most cases, the agent-based models have been very simple and do not realize the potential of the approach $[3,13]$. These models are mostly developed to investigate the effects of a specific transport measure concerning a specific scenario. Furthermore, they do not include all modes of transportation. The input variables, the model construction, and the collected output are very much chosen with a specific scenario in mind. Therefore, these models cannot investigate the effects of various kinds of transport measures in different scenario settings. This means that they are unable to be used as a decision support system to support transport policy making. There are also frameworks for implementing largescale agent-based transport simulations, e.g. MATSim [4], which focus on traffic flows and vehicles rather than travel option choices and travelers.

The majority of the traditional models are mode choice models [12], which aim to answer how many travelers will switch to another mode of transport in case of any change in transport system [2]. However, in addition to the choice of transport mode, there are also other important aspects of travel behavior, such as route choice and departure time choice [10]. In order to have a comprehensive and accurate impact assessment, we claim there is a need to investigate the impact on all aspects of travel. 


\section{$3 \quad$ Proposed model}

In the proposed model, we use agent based modeling, which enables us to include each individual's preferences and characteristics into the travel choice modeling. Passengers are modeled as agents. The decision making process of travelers when choosing between the available travel alternatives is to some extent individual and not the same for all travelers. This means that there is no objectively optimal travel choice from point $\mathrm{A}$ to point $\mathrm{B}$ in a given situation. Therefore, we assume that the "best" travel alternative can be different for different travelers. In our model, the choices between alternatives are based on four main factors: cost, time, convenience, and social norm. The perceived value (priority) of each of these factors is typically different for each traveler and depends on:

- The traveler's characteristics; refers to the attributes of each traveler and have a determining role in the choice of travel. Examples include socio-economic attributes and geographical location of home and workplace.

- The available travel options at the time of travel and their related cost, travel time, $\mathrm{CO}_{2}$ emission, number of changes, and walking and cycling distance.

- Contextual factors, e.g. the current and predicted weather.

Web-services are used in this model for data collection. We generate the travel alternatives for a traveler from point $\mathrm{A}$ to point $\mathrm{B}$, using the web services provided by online travel planners. The use of online travel planners for generating travel alternatives is a novel approach which enables us to capture the most recent information about route alternatives and their relevant characteristics such as cost and travel time. Furthermore, it provides the model with real-time information that adapts automatically with updates, e.g., if the bus schedules change, this change will be automatically updated in the simulation model. Due to recent developments in application of information systems for online trip planning, nowadays most travelers have access to online travel planners and are able to retrieve almost all the possible travel alternatives at the time of departure. Therefore, we believe integration of web services of online travel planners in the simulation model makes the model very close to reality and is highly consistent with the way travelers choose to travel in everyday life. We use the route alternatives' data gathered from web services as input in the decisionmaking model.

\subsection{Passenger behavior modeling}

For modeling the individual's travel decision-making we use the theory of planned behavior, which is an extension of the theory of reasoned action [1]. It assumes that humans are rational and they make systematic use of information available to them while they also consider the implications of their actions before they decide for a certain behavior. In our model, we consider cost, travel time, and convenience as the rational factors that affect the choice of travel. A rational agent aims to maximize the utility and hence minimize cost and travel time and maximize convenience. However, 
travelers do not always act completely rational. Social norms and personal values may affect the choice of travel. The theory of planned behavior complements the theory of reasoned action by adding the concept of social norm. Environmental awareness of the travelers is modeled as social norm in our model. The theory of planned behavior has also the possibility to cover the behaviors that are not fully under an individual's volitional control. This is very important in travel decision-making where the choice of travel by each individual is not only influenced by her characteristics, attitudes, and subjective norms, but also on intervening environmental conditions, such as the weather which we have included as a contextual factor in the proposed model.

As mentioned earlier, we use four main categories of factors when making travel choices: cost, time, convenience, and social norms. The significance of each of these factors is determined by each traveler's individual characteristics and contextual factors. In our model, the value of each of these factors is calculated based on traveler's characteristics and weather conditions. It has been argued that the factors influencing choice of travel can be valued differently for different travel purposes [8,19]. We have included a weight for each of the factors (i.e., cost, time, convenience, $\mathrm{CO}_{2}$ emission) in order to be able to change the significance of each factor for different travel purposes. These weights will also be used for calibration purposes. For the decisionmaking model, we use the weighted sum model [18].

The traveler characteristics that we include in our model are: age, income, work flexibility, environmental awareness, work and home address, working start and end times, access to car, and access to bicycle at home and work. We use work and home address, working hours, access to car, and access to bicycle at home and work directly when generating the travel alternatives, while the other mentioned factors are used for choosing between different travel alternatives. In Table 1 we describe a model of how all these factors can potentially affect the choice of travel and how they interrelate. The main factors influencing travel behavior are listed as columns in Table 1, while the rows are referring to traveler's characteristics and contextual factors. We believe that the income level of the traveler can affect the traveler's perception of travel costs. We use this concept to calculate the value of cost for each traveler; the higher income decreases the influence of the cost on the travel decision of the traveler [5,12]. For calculating the value of time, we use the traveler's work flexibility factor. We assume that more flexible working hours decreases the value of travel time to some extent.

It is shown that travelers who are more environmentally conscious tend to take the travel options that have less negative effects on the environments, or more specifically, the travel options that generate least $\mathrm{CO}_{2}$ emissions [11]. Therefore, in our model we assume that the amount of $\mathrm{CO}_{2}$ emission can affect the individual's choice of transport, depending on the individual's level of eco-friendliness.

We assume that convenience is comprised of walking distance, cycling distance, and number of changes for a travel option. The number of changes is defined as the number of transfers between vehicles in order to complete a journey. It has a negative effect on the choice of a travel option; the more interchanges in a travel option, the less convenient it is perceived [9]. Moreover, the number of changes of a travel option makes it less attractive the older you are [14]. Furthermore, we assume that the interchange between vehicles is less convenient in case of bad weather conditions. 
Heinen et al. [8] reviewed the factors influencing cycling and indicated that there is a relationship between age and cycling, although it is not universal. While most studies have concluded that the willingness to bike decline with age, there are also some other studies that have not found any significant relation between age and cycling. Weather has also a high influence on the distance the individuals are willing to cycle. High precipitation and low temperature have been found as the most significant weather conditions influencing cycling level. There appears to be no significant relation between the other factors (e.g., income) and cycling [8]. In our model, we assume that convenience is more important for older travelers. Moreover, bad weather conditions (e.g., rain, snow, or low temperature) decrease the convenience of travel options with long walking distance, cycling distance, and higher number of changes.

Table 1. Interrelationship between the factors influencing choice of travel

\begin{tabular}{|c|c|c|c|c|c|c|c|}
\hline \multirow{2}{*}{} & \multicolumn{6}{c|}{ Travel option's attributes } \\
\cline { 3 - 8 } & Cost & Time & Environ. impact & \multicolumn{2}{c|}{ Convenience } \\
\cline { 3 - 8 } & $\begin{array}{c}\text { Travel } \\
\text { costs }\end{array}$ & $\begin{array}{c}\text { Travel } \\
\text { time }\end{array}$ & $\mathrm{CO}_{2}$ emission & $\begin{array}{c}\text { No. of } \\
\text { changes }\end{array}$ & $\begin{array}{c}\text { Walking } \\
\text { distance }\end{array}$ & $\begin{array}{c}\text { Cycling } \\
\text { distance }\end{array}$ \\
\hline \multirow{2}{*}{$\begin{array}{c}\text { Traveler's } \\
\text { characteristics }\end{array}$} & Age & & & & $*$ & $*$ & $*$ \\
\cline { 2 - 8 } & Income & $*$ & & & & & \\
\cline { 2 - 8 } & Work flex. & & $*$ & & & & \\
\cline { 2 - 8 } & Eco-friend & & & & $*$ & & $*$ \\
\hline Contextual & Weather & & & & & & \\
\hline
\end{tabular}

\subsection{Decision making model}

We use a utility function in order to calculate a score for each travel option. The factors influencing travel behavior are the main components of the model. The values of these components are a function of the characteristics of the traveler and contextual factors. Actually, the score represents disutility of the travel option; therefore, the travel option with the lowest score will be selected as the best travel option.

The components of the scoring function have different scales and unit of measurements, and some are quantitative (e.g., age and income), while the others are qualitative or categorical (e.g., weather and work flexibility). In order to avoid domination of larger values, make the components consistent, and neutralize the unit of measurement of the values, we normalized the attributes of travel options; corresponding to the columns in Table 1. These normalized attributes are referred as relative values in the equation (1), e.g., rel $_{\text {oat }}^{\text {envimpact }}$ refers to the relative environmental impact of travel option $o$ for agent $a$. Moreover, we have converted all the characteristics of the travelers and contextual factors to categorical data. These values are called as $v a l_{a}^{x x}$ in the equation (1), where $x x$ are the factors of the traveler $a$ mentioned in the rows of Table 1 and $v a l_{t}^{w t h}$ is the value assigned to the weather condition of trip $t$. As mentioned earlier, we also assign a weight to each factor for calibration purposes, i.e., $W_{\text {cost }}, W_{\text {time }}, W_{\text {conv }}, W_{\text {eco }}$ refering to the weight of cost, time, convenience, and ecofriendliness, respectively. These weights can also be used to change the importance of each factor according to travel motive, e.g. traveling to work or just for leisure. The score for travel option $o$ for agent $a$ and trip $t$ is calculated as below: 
$S_{\text {oat }}=W_{\text {cost }} * \mathrm{rel}_{\text {oat }}^{\text {cost }} *$ val $_{a}^{\text {income }}+W_{\text {time }} *$ rel $_{\text {oat }}^{\text {time }} *$ val $_{a}^{\text {workflex }}+W_{\text {conv }} *$ $\operatorname{rel}_{\text {oat }}^{\text {conv }} * v_{\text {al }}^{\text {age }}+W_{\text {conv }} * \operatorname{rel}_{\text {oat }}^{\text {conv }} * v_{\text {al }}^{\text {wth }}+W_{\text {eco }} * \operatorname{rel}_{\text {oat }}^{\text {envimpact }} * v_{\text {al }}^{\text {eco }}$

As mentioned earlier, convenience is determined by the three factors of walking distance, cycling distance, and the number of changes of the travel option $o$ for agent $a$ in our model, and it is calculated as:

$r e l_{\text {oat }}^{\text {conv }}=r e l_{\text {oat }}^{\text {wlkDis }}+\operatorname{rel}_{\text {oat }}^{\text {cycDis }}+\operatorname{rel}_{\text {oat }}^{\text {noofChange }}$

The relative time and cost are calculated by normalizing the cost and time of a travel option with respect to the other travel options of traveler $a$ for trip $t$. In the below equations, $O$ refers to the collection of all travel options of trip $t$ for traveler $a$, i.e.,

$r e l_{\text {oat }}^{\text {cost }}=\frac{\text { Cost }_{\text {oat }}}{\sum_{o^{\prime} \in O} \text { Cost }_{o^{\prime} a t}}, \quad r e l_{\text {oat }}^{\text {time }}=\frac{\text { Time }_{\text {oat }}}{\sum_{o^{\prime} \in O \text { Time }_{o^{\prime}} \text { at }}^{\text {Time }}}$,
rel $_{\text {oat }}^{\text {envImpact }}=\frac{\text { Co2Emission }_{\text {oat }}}{\sum_{o^{\prime} \in O} \text { Co2Emission }_{o^{\prime} a t}}$

The factors for convenience are also normalized as shown below. For example, for calculating the relative environmental impact of a travel option $o$, the $\mathrm{CO}_{2}$ emission of that travel option will be divided by the sum of $\mathrm{CO}_{2}$ emissions over all the travel options $O$ for trip $t$ of the agent $a$ :

rel $_{\text {oat }}^{\text {wlkDis }}=\frac{\text { WalkingDistance }_{\text {oat }}}{\sum_{o^{\prime} \in O} \text { WalkingDistance }_{o^{\prime} a t}}$, rel $_{\text {oat }}^{\text {cycDis }}=\frac{\text { CyclingDistance }_{\text {oat }}}{\sum_{o^{\prime} \in O} \text { CyclingDistance }_{o^{\prime}} \text { at }}$,

rel $_{\text {oat }}^{\text {noofChange }}=\frac{\text { NoOfChanges }_{\text {Oat }}}{\sum_{o^{\prime} \in O^{\text {NoOfChanges }}} \text { Not }^{\prime}}$

The categories of age, income, work flexibility, environmental awareness (i.e., ecofriend) and weather are specified in the Table 2. All the values are considered to be a number between 0 and 1 which determines the value of the corresponding factor in the model, e.g., val ${ }^{\text {age }}$. For example, we assume a higher income value for lower income, which means that the value of travel cost will be lower for a traveler with higher income. The values used are just preliminary estimations and will be further analyzed and validated in future experiments.

Table 2. The categorization of characteristics of travelers and contextual factor $\left(\mathrm{val}^{\mathrm{xx}}\right)$

\begin{tabular}{|c|c|c|}
\hline Variable & Range & Value \\
\hline \multirow{4}{*}{ Age } & $15-25$ & 0.1 \\
\cline { 2 - 3 } & $25-35$ & 0.3 \\
\cline { 2 - 3 } & $35-55$ & 0.5 \\
\cline { 2 - 3 } & $55-70$ & 0.7 \\
\cline { 2 - 3 } & +70 & 0.9 \\
\hline \multirow{4}{*}{$\begin{array}{c}\text { Income } \\
\text { (monthly) }\end{array}$} & +100000 & 0.1 \\
\cline { 2 - 3 } & $50000-100000$ & 0.3 \\
\cline { 2 - 3 } & $25000-50000$ & 0.5 \\
\cline { 2 - 3 } & $15000-25000$ & 0.7 \\
\hline
\end{tabular}

\begin{tabular}{|c|c|c|}
\hline Variable & Range & Value \\
\hline \multirow{2}{*}{$\begin{array}{c}\text { Work } \\
\text { flexibility }\end{array}$} & high & 0.4 \\
\cline { 2 - 3 } & average & 0.5 \\
\cline { 2 - 3 } Eco-friend & low & 0.6 \\
\cline { 2 - 3 } & not concerned & 0.3 \\
\cline { 2 - 3 } & medium engagement & 0.5 \\
\hline \multirow{3}{*}{ Weather } & high engagement & 0.7 \\
\cline { 2 - 3 } & Average (no rain or snow and temp $\left.0-10^{\circ} \mathrm{C}\right)$ & 0.2 \\
\cline { 2 - 3 } & bad (rain or snow, or temp $\left.<0{ }^{\circ} \mathrm{C}\right)$ & 0.8 \\
\hline
\end{tabular}




\subsection{Generation of travel alternatives}

For each trip of a traveler, the model generates a set of travel options, using web services of online travel planners. The attributes that are extracted from the web service, for each travel option include route specification, travel time, cost, $\mathrm{CO}_{2}$ emission, and the number of changes. These attributes are later used as input data in the traveler decision-making model.

Waking, cycling, and driving travel options refer to the options that use only one of walking, cycle, and car as the mode of transport from origin to the destination. Public transport options refer to the travel options that use public transport together with some short walking to public transport stops or transferring between stops. The time and distance of these short walks are taken into account in the simulation. We further complete the set of travel options by adding additional options where we have replaced long walking distances from origin (A) to a station $\left(\mathrm{A}^{\prime}\right)$, and from a station $\left(\mathrm{B}^{\prime}\right)$ to destination $(\mathrm{B})$ by cycling. Long walking is defined as walking distances $(d)$ between 200 meters and 6000 meters. The different travel options from point $A$ to point B are illustrated in Fig. 1.

We use Google Maps direction API ${ }^{1}$ to generate walking, cycling, and driving travel options. The cost for the driving option is calculated based on the travel distance and possibly parking fees. To generate the public transport travel options, web services by the public transport providers in the area are needed. In our case, the most southern part of Sweden, this is provided by Skånetrafiken Open API ${ }^{2}$. It provides cost, travel time, number of changes, $\mathrm{CO}_{2}$ emission, and walking distance of each travel option from point $\mathrm{A}$ to point $\mathrm{B}$ in a specified time and date. We have also used an API called "Commute Greener" ${ }^{3}$ in order to calculate the amount of $\mathrm{CO}_{2}$ emission for car users. The output of the APIs are in $\mathrm{XML}^{4}$ or $\mathrm{JSON}^{5}$ schema format. These schemas are parsed in order to extract relevant information (e.g. travel alternatives, travel time, cost, and $\mathrm{CO}_{2}$ emissions of each alternative).

A

A

A

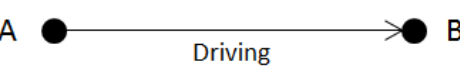

A

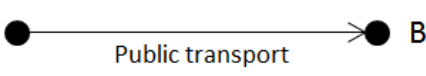

A

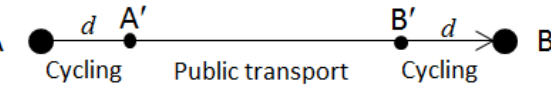

A

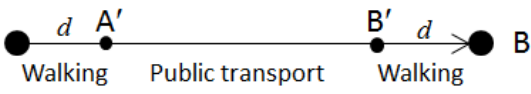

A

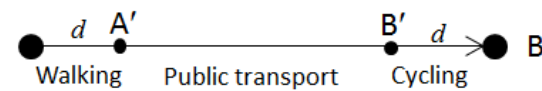

A

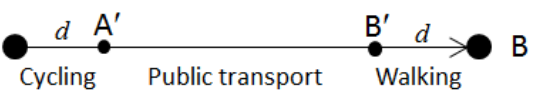

Fig. 1. All considered combinations of transport modes for generating travel options of a trip

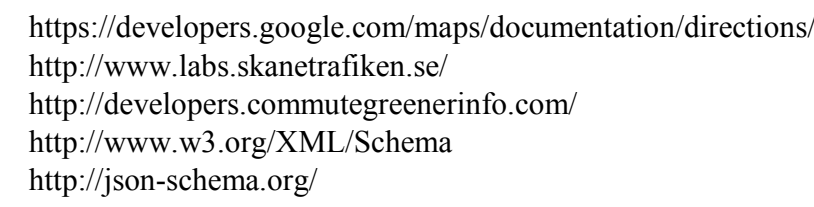


When generating the travel alternatives from web services, the characteristics of the traveler are taken into account, i.e., in case the traveler has no access to bike at home, the travel options which have cycling from home will not be generated for that specific traveler, or if the traveler has no access to car, driving options will not be generated. Furthermore, the source and destination of travel options for a specific traveler and also departure time of the travel are set according to traveler's information i.e., work/home address and working hours.

Since it is not possible to get detailed weather forecast for more than 14 days ahead, we used historical weather data of the same day as the travel date from the last year provided by Weather Underground service ${ }^{6}$. We use the temperature, precipitation, and weather conditions (i.e., rainy or snowy) of the same day in the last year. The sequence of the model is illustrated in Fig. 2.

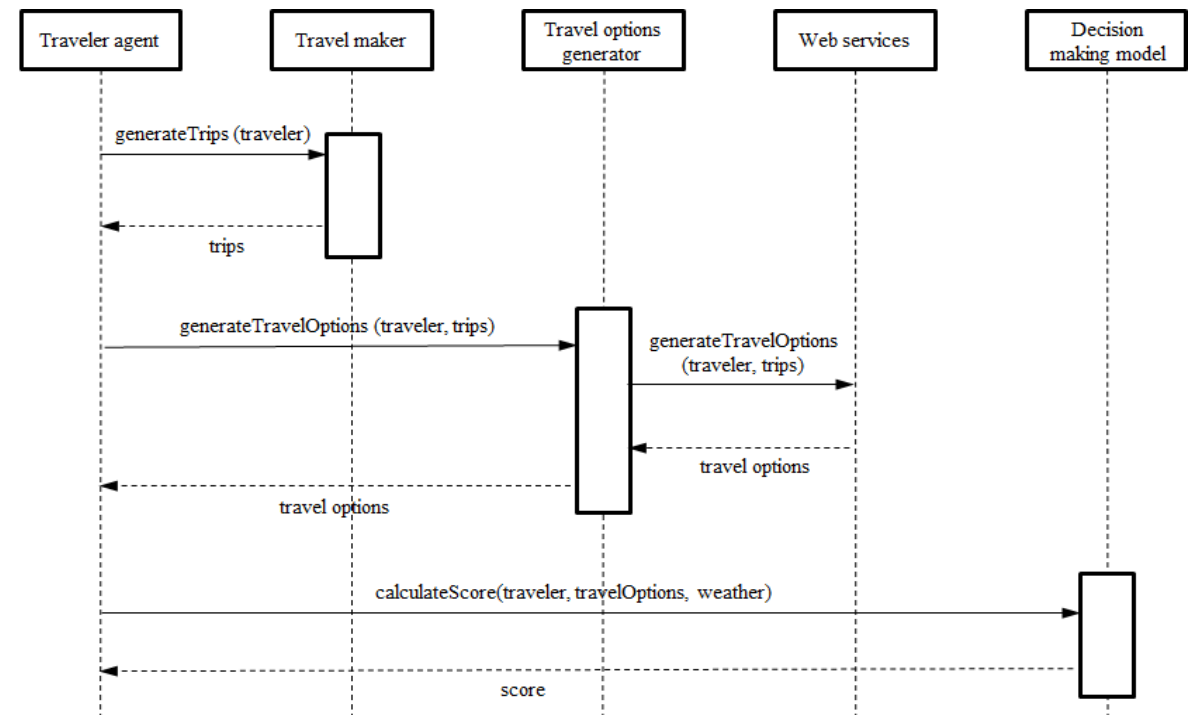

Fig. 2. Sequence diagram of the model

\section{$4 \quad$ Case study}

In this section, we present a small case study of the proposed model, which is implemented within a prototype. In this first basic experiment, we use a small sample population of 16 real travelers from the cities Malmö and Lund in Sweden who commute between the cities for work and study. The population sample provide their sociodemographic attributes including their work and home addresses.

For each traveler, we generate two trips for commuting to work and back to home using the traveler's home and work address and work schedule. Travel alternatives are

6 http://www.wunderground.com/ 
generated for each trip using web services. A score is calculated for each travel option according to our decision making model.

We study three scenarios; in the first scenario, we simulate the current situation (CS), in the second scenario we examine the effects of reducing public transport fare to half price (HP). The third scenario concerns doubling the public transport fare (DP). We investigate how these changes to the public transport fare are expected to affect the choice of travel and modal share of the travelers using our implemented prototype. We run the simulation for ten randomly generated days with different weather conditions. The following diagrams (Fig. 3) illustrate how changing the public transport fare might affect the modal share, amount of $\mathrm{CO}_{2}$ emission (estimated $\mathrm{CO}_{2}$ footprint per traveler), and travel cost and time for the travelers' commuting during 10 random simulated days. It can be seen from the diagrams that reducing the public transport fare significantly affects the choice of travel and shifts the modal share from private vehicle use to public transport. The walking and cycling share decrease in the DP scenario. It is mostly due to the small walking distances between public transport stations, or also due to the travelers who have combined cycling and public transport. When the travelers switch from public transport to private car, the mentioned walking and cycling links will also disappear. Furthermore, it can be seen from the Fig. 3 that the amount of $\mathrm{CO}_{2}$ emission will decrease in case of reducing public transport fare, which can be due to the shift from car use to public transport. Moreover, the selected travel option of the agents cost more when we increase public transport fare, which can be both because of the increase in public transport fare and the shift to car that is a more expensive mode of transport.
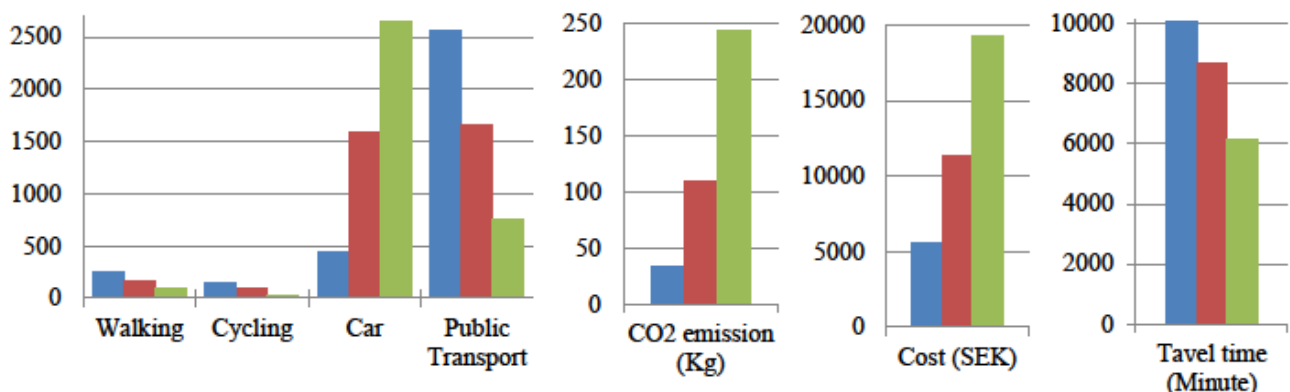

Fig. 3. Modal share (Km), $\mathrm{CO}_{2}$ emission, cost and time of selected travel options for 10 random days. Blue $=$ half price public transport, red $=$ current price public transport, and green $=$ double price public transport scenario.

\section{Concluding remarks}

This paper has presented an innovative multi-agent based simulation model for modeling travel behavior of passengers. The aim is to support policy makers and urban transport planners in estimating the effects of new transport measures, e.g. policies and infrastructure investments. Some of the characteristics of our model are: 
- It uses combinations of transport modes for generating travel alternatives.

- It uses web services of on-line travel planners to generate travel options

- It investigates mode, route, and departure time choice of travelers

- It considers a range of factors influencing the choice of travel in the travel behavior model, i.e., traveler characteristics, contextual data, and social norm.

Using online travel planners enabled us to access real-time network data that to a large extent corresponds to the data that the real travelers are able to access. It also helped reducing the effort and computation required for generating travel alternatives, calculating travel time, cost, and emissions. It should also be noted that the use of web services as an input data source may have some potential drawbacks. Firstly, the web services might be temporarily down. Secondly, the performance of web services at a given time might be influenced by the load of the service at that time. Although these potential issues can affect the performance of the model, we did not notice any of these problems during the development and testing of the model. Furthermore, to support scalability of this approach, we are using caching of travel options in order to minimize the number of requests. It is also possible to run our own server in future.

We have also described the decision-making model and how the travelers choose between generated travel alternatives. We have included convenience factor in our model, which is a combination of walking distance, cycling distance and the number of changes in a travel alternative. The initial results from our case study show the feasibility of our approach in travel behavior modeling.

Future work consists of improving the decision making model such as including more factors (e.g. reliability), and investigating the best way to model the correlation between factors, e.g. how income influence the value of travel time. We will also validate the factors considered in the decision-making module of the model and their influence on travelers' decision-making. The convenience factor can be further developed to include more factors such as parking facilities. At this stage, social norms are modeled by environmental awareness, however, this will be further developed in future versions of the model. The interaction between travelers will also be considered in the further work, e.g. in car-pooling options. We have also planned to apply synthetic population methods in order to generate large populations of realistic agents. The model will also be further tested through more complicated scenarios, where the effects of combinations of transport measures are being investigated.

Acknowledgements. We wish to thank K2 - The National Knowledge Centre for Public Transport, and the National ITS Postgraduate School for funding this research.

\section{References}

1. Ajzen, I. (1991). The theory of planned behavior. Organizational Behavior and Human Decision Processes, 50(2), 179-211

2. Alpizar, F., \& Carlsson, F. (2003). Policy implications and analysis of the determinants of travel mode choice: an application of choice experiments to metropolitan Costa Rica. Environment and Development Economics, 8(04), 603-619. 
3. An, S., Cui, J. X., \& Li, L. Y. (2011). Agent-based approach to model commuter behaviour's day-to-day dynamics under pre-trip information. IET Intelligent Transport Systems, 5(1), 70-79.

4. Balmer, M., Rieser, M., Meister, K., Charypar, D., Lefebvre, N., Nagel, K., \& Axhausen, K. (2009). MATSim-T: Architecture and simulation times. Multi-agent systems for traffic and transportation engineering, 57-78.

5. De Witte, A., Hollevoet, J., Dobruszkes, F., Hubert, M., \& Macharis, C. (2013). Linking modal choice to motility: A comprehensive review. Transportation Research Part A: Policy and Practice, 49, 329-341.

6. Gilbert, N., \& Troitzsch, K. (2005). Simulation for the social scientist. Open University Press.

7. Hajinasab, B., Davidsson, P., \& Persson, J. A. (2014). A Survey on the Use of Computational Models for Ex Ante Analysis of Urban Transport Policy Instruments. Procedia Computer Science, 32, 348-355.

8. Heinen, E., van Wee, B., \& Maat, K. (2010). Commuting by bicycle: an overview of the literature. Transport reviews, 30(1), 59-96.

9. Hine, J., \& Scott, J. (2000). Seamless, accessible travel: users' views of the public transport journey and interchange. Transport Policy, 7(3), 217-226.

10. Horton, F. E. (1972). Behavioral models in transportation planning. Transportation Engineering Journal of the American Society of Civil Engineers, 98, 411-419.

11. Johansson, M. V., Heldt, T., \& Johansson, P. (2006). The effects of attitudes and personality traits on mode choice. Transportation Research Part A: Policy and Practice, 40(6), 507-525.

12. Lave, SC. A. (1969). A behavioral approach to modal split forecasting. Transportation Research, 3(4), 463-480.

13. McDonnell, S., \& Zellner, M. (2011). Exploring the effectiveness of bus rapid transit a prototype agent-based model of commuting behaviour. Transport Policy, 18(6), 825-835.

14. Nitta, Y., \& Do, G. (1998). Transportation mode-change model to special bus incorporating generalized time. In 8th International Conference on Transport and Mobility for Elderly and Disabled People.

15. Ramstedt, L. (2008). Transport policy analysis using multi-agent-based simulation, Doctoral Dissertation Series No. 2008:09, Blekinge Institute of Technology, Sweden.

16. Takama, T., \& Preston, J. (2008). Forecasting the effects of road user charge by stochastic agent-based modelling. Transportation Research Part A: Policy and Practice, 42,738-749.

17. Teodorovic, D. (2003). Transport modeling by multi-agent systems: a swarm intelligence approach. Transportation Planning and Technology, 26(4), 289-312.

18. Triantaphyllou, E. (2000). Multi-criteria decision making methods a comparative study. Springer.

19. Walle, S. V., \& Steenberghen, T. (2006). Space and time related determinants of public transport use in trip chains. Transportation Research Part A: Policy and Practice, 40(2), 151-162. 